\title{
Effect of Ionized Calcium Level on the Prognosis and Mortality of Patients with Pulmonary Embolism
}

\author{
Hatice Seyma Akca ${ }^{1}$, Ramazan Koylu ${ }^{1,}$, , Nazire Belgin Akilli ${ }^{1}$, Ayse Isik Kinaci ${ }^{1}$, Oznur Koylu ${ }^{2}$, \\ Basar Cander ${ }^{3}$ \\ ${ }^{1}$ Emergency Department, Konya Training and Research Hospital, University of Health Sciences, Konya, Turkey \\ ${ }^{2}$ Biochemistry Department, Konya Training and Research Hospital, University of Health Sciences, Konya, Turkey \\ ${ }^{3}$ Emergency Department, Meram Faculty of Medicine, University of Necmettin Erbakan, Konya, Turkey
}

Email address:

drkoylu@yahoo.com (R. Koylu)

${ }^{*}$ Corresponding author

\section{To cite this article:}

Hatice Seyma Akca, Ramazan Koylu, Nazire Belgin Akilli, Ayse Isik Kinaci, Oznur Koylu, Basar Cander. Effect of Ionized Calcium Level on the Prognosis and Mortality of Patients with Pulmonary Embolism. American Journal of Internal Medicine. Vol. 6, No. 1, 2018 , pp. $20-24$. doi: $10.11648 /$ j.ajim.20180601.13

Received: December 20, 2017; Accepted: February 9, 2018; Published: March 6, 2018

\begin{abstract}
Objective: The aim of this study was to investigate the effect of ionized calcium level on the prognosis and mortality of patients with pulmonary embolism. Materials and method: A total of 165 patients over 18 years of age, who had been hospitalized due to pulmonary embolism were retrospectively evaluated. A significant relation was determined between mortality and low systolic blood pressure $(\mathrm{p}<0.05)$, low diastolic blood pressure $(\mathrm{p}<0.05)$ and tachycardia $(\mathrm{p}<0.05)$. The relation between mortality and high levels of urea $(p<0.05)$, creatinine $(p<0.05)$, d-dimer $(p<0.05)$, CK-MB $(p<0.05)$, troponin $(p<0.05)$ and lactate $(p<0.05)$ was also significant. The relation between mortality and duration of intensive care unit stay $(p<0.05)$, hospital stay $(p<0.05)$ and duration of mechanical ventilation $(p<0.05)$ was also significant, whereas no relation was determined between the ionized calcium level and mortality $(\mathrm{p}=0.154)$. However, a significant relation was determined between the high level of ionized calcium and duration of mechanical ventilation $(\mathrm{p}=0.019)$. Additionally, the relation between right bundle branch block in ECG and mortality was found to be significant $(p<0.05)$. Conclusion: Although no direct relation was determined between the level of ionized calcium and mortality in pulmonary embolism, it may be useful in predicting the duration of mechanical ventilation.
\end{abstract}

Keywords: Pulmonary Embolism, Ionized Calcium, Prognosis

\section{Introduction}

Pulmonary embolism (PE) is the obstructive disease of the pulmonary arterial system at varying degrees and localizations that arise from embolization of thrombus or substances other than thrombus (such as tumor cells, fatty tissue, septic material, air or amniotic fluid), which is usually derived from the deep femoral veins.

It has been the third most common cause of cardiovascular disease-related death after coronary artery disease and stroke [1].

The prognosis depends on factors such as age, gender and whether the risk factors are permanent or transient.

The mortality rates significantly increase in the presence of acute symptoms at the onset, such as syncope, tachycardia (>100/min), tachypnea ( $>24 / \mathrm{min})$, hypotension and RV hypertrophy [2].

Several authors have reported increased mortality rates in case of hypocalcemia in patients in intensive care units, and a negative relation between hypocalcemia and Acute Physiology and Chronic Health Evaluation (APACHE) II score [3].

Cause of hypocalcemia in patients in the intensive care unit has not been clearly understood. Insufficient parathormone $(\mathrm{PTH})$ release or activation, reduced intra- and extra-cellular formation of vitamin D3, and increased calcium storage have been indicated as the causes of hypocalcemia among those patients [3]. 
The normal range of ionized calcium level is $4.5-5.6 \mathrm{mg} / \mathrm{dl}$, which is also expressed as 1.1-1.4 $\mathrm{mmol} / \mathrm{l}$ in international units [4].

Calcium is essential for many cellular functions including muscle contraction, vascular tension, enzyme activation, hormone release, neurotransmission, membrane potential, blood coagulation and intracellular transport, and intra- and extra-cellular levels of calcium are precisely controlled by the parathyroid hormone $[5,6]$.

There is yet no clear statement presenting a relationship between pulmonary thromboembolism and ionized calcium. The aim of this study was to investigate the level and effect of ionized calcium on the prognosis of patients with pulmonary embolism.

\section{Materials and Method}

Our study included patients over 18 years of age with pulmonary embolism, who had presented to the emergency unit of a third step training and research hospital between January 1, 2009 and October 30, 2014. All patient data were accessed by the automation system of the hospital and archive records. Those with missing data or whose file was not found, were not included in the study. A total of 165 patients with the pre-diagnosis of pulmonary embolism were included in the study. Identity information, age, physical examination findings (body temperature, pulse, arterial tension), blood gas analyses, d-dimer, CK (creatine kinase), CK-MB, HGB (hemoglobin), MCV (mean corpuscular volume), WBC (leukocyte count), PLT (platelet count), NEU (neutrophil count), LYM (lymphocyte count), urea, creatinine, $\mathrm{Na}, \mathrm{K}$ and $\mathrm{Ca}$ levels, durations of hospital and intensive care unit stay, and duration of mechanical ventilation were recorded. Presence of ECG, ECHO and CT examinations, and presence of any finding in these examinations were investigated using the automation system of the hospital and archive records. The discharge and mortality statuses were also evaluated.

Statistical analysis; The statistical Package for Social Sciences (SPSS) for Windows, version 15.0 was used for the statistical analysis. Suitability of the variables to normal distribution was investigated using the visual (histogram) and analytic methods (kolmogrov-smirnov/Shapiro-Wilk tests). Descriptive analyses were expressed as mean \pm standard for normally distributed variables and median and interquartile range (IQR) for non-normally distributed variables. The patients were divided into two groups according to data on in-hospital mortality and duration on mechanical ventilation. Inter group comparisons of clinical and laboratory characteristics were made using the student-t test and the Mann-Whitney $U$ test for numeric variables, and the chisquare or Fisher's exact test for the categorical variables. The comparisons between the ECG, ECHO and CT results of patients with and without mechanical ventilation were compared using the chi-square or the Fisher's exact tests. Coefficient of correlation and statistical significance were calculated using the spearman test for the relationships between variables including at least one non-normally distributed variable. Type-1 error level of statistical significance was accepted as $5 \%$.

\section{Findings}

The study included 165 patients with pulmonary embolism. The median age was 72 (IQR:19). Among the participants, 94 $(57 \%)$ were female and $71(43 \%)$ were male. The median level of body temperature was 36.5 (IQR:0.7) and median value of pulse was 92.5 (IQR:19.5). The mean values of systolic and diastolic blood pressure were $113.04 \pm 18.3$ and $68.8 \pm 13.5$, respectively (Table 1 ).

Table 1. Demografic and laboratuar findings.

\begin{tabular}{|c|c|}
\hline Age, median(IQR) & 72(19) \\
\hline Female & $94(57)$ \\
\hline Male & $71(43)$ \\
\hline TİP 2 DM, n(\%) & $19(11.5)$ \\
\hline CAD, n(\%) & $17(10.3)$ \\
\hline $\mathrm{HT}, \mathrm{n}(\%)$ & $26(15.8)$ \\
\hline CRF n(\%) & $3(1.8)$ \\
\hline SVD, $n(\%)$ & $10(6.1)$ \\
\hline $\mathrm{KOAD}, \mathrm{n}(\%)$ & $41(24.8)$ \\
\hline $\mathrm{CCF}, \mathrm{n}(\%)$ & $16(9.7)$ \\
\hline OTHER, n(\%) & $39(23.6)$ \\
\hline Pulse, median(IQR) & $92.5(19.75)$ \\
\hline Sistolik TA, mmhg, mean( SD) & $113.04 \pm 18.3$ \\
\hline Diastolik TA, mmhg, mean(SD) & $68.8 \pm 13.5$ \\
\hline Fever, median(IQR) & $36.5(0.7)$ \\
\hline BUN, mg/dl, median(IQR) & $53(49.5)$ \\
\hline Creatinin, mg/dl, median (IQR) & $0.95(0.65)$ \\
\hline $\mathrm{Na}, \mathrm{mEq} / \mathrm{L}$, mean(SD) & $136.95 \pm 5.44$ \\
\hline $\mathrm{K}, \mathrm{mEq} / \mathrm{L}$, mean $(\mathrm{SD})$ & $4.5 \pm 0.85$ \\
\hline $\mathrm{Ca}, \mathrm{mg} / \mathrm{dl}$, mean(SD) & $8.4 \pm 0.72$ \\
\hline Troponin, ng/ml, median(IQR) & $0.04(0.12)$ \\
\hline CK, u/l, median(IQR) & $85(57)$ \\
\hline CK-MB, ng/ml, median(IQR) & $18(21.5)$ \\
\hline $\mathrm{Ph}, \operatorname{median}(\mathrm{IQR})$ & $7.4(0.13)$ \\
\hline Satüration, median(IQR) & $93(7)$ \\
\hline $\mathrm{PO}_{2}$, mmhg, median(IQR) & $61.1(18.4)$ \\
\hline $\mathrm{PCO}_{2}, \mathrm{mmhg}$, mean(SD) & $37.09 \pm 13.3$ \\
\hline $\mathrm{Hco}_{3}, \mathrm{meq} / \mathrm{l}$, mean(SD) & $21.30 \pm 5.69$ \\
\hline Laktat, mmol/l, median(IQR) & $2(1.45)$ \\
\hline İonize calsium, mmol/1, mean(SD) & $0.82 \pm 0.35$ \\
\hline D-dimer, ng/ml, median(IQR) & $4.3(5.05)$ \\
\hline $\mathrm{Hgb}, \mathrm{mg} / \mathrm{dl}$, mean(SD) & $12.01 \pm 2.17$ \\
\hline WBC,mm3,median(IQR) & $9.87(6.62)$ \\
\hline İntensive care hospital stay, median (IQR) & $1(6.5)$ \\
\hline Hospital stay, median(IQR) & $8(9)$ \\
\hline MV, median(IQR) & $0(1)$ \\
\hline
\end{tabular}

History of the patients included coronary artery disease (CAD) in $17(10,3 \%)$, hypertension in $26(15,8 \%)$, cerebrovascular disease (CVD) in $10(6,1 \%)$, diabetes mellitus (DM) in 19 (11,5\%), chronic renal failure (CRF) in 3 $(11,5 \%)$, chronic obstructive pulmonary disease (COPD) in $41(24,8 \%)$, congestive heart failure (CHF) in $16(9,7 \%)$ and others in $39(23,6 \%)$.

Pathological ECG findings were observed in 117 of the 165 participants $(70.9 \%)$. The most common finding of the patients with abnormal ECG was atrial fibrillation, which was observed in 37 patients (22.4), and the second most 
common finding was sinus tachycardia, which was observed in 36 patients $(21.8 \%)$. The ECG findings have been presented in Table 2 .

Table 2. EKG findings.

\begin{tabular}{lll}
\hline EKG findings & + & - \\
\hline Normal EKG & $48(\% 29.1)$ & $117(\% 70.9)$ \\
Sinus tachycardia & $36(\% 21.8)$ & $129(\% 78.2)$ \\
ST depretion & $8(\% 4.8)$ & $157 \%(95.2)$ \\
ST elevation & $2(\% 1.2)$ & $163(\% 98.8)$ \\
T wave change & $6(\% 3.6)$ & $159(\% 96.4)$ \\
S1Q3T3 & $1(\% 0.6)$ & $164(\% 99.4)$ \\
Atrial Fibrilation & $37(\% 22.4)$ & $128(\% 77.6)$ \\
Right branch block & $19(\% 11.5)$ & $146(\% 88.5)$ \\
\hline
\end{tabular}

ECHO findings were observed in 94 patients. Pulmonary tension was the most common finding observed among these patients, which was observed in $49(52.1 \%)$. The least common finding was low EF. The ECHO findings have been presented in Table 3.

Table 3. EKO findings.

\begin{tabular}{lll}
\hline EKO finding & + & - \\
\hline Right gaps wide & $32(\% 34)$ & $62(\% 66)$ \\
Hypokinetic septum & $9(\% 9.6)$ & $85(\% 90.4)$ \\
Pulmoner hipertantion & $49(\% 52.1)$ & $45(\% 47.9)$ \\
Low EF & $7(\% 7.4)$ & $87(\% 92.6)$ \\
\hline
\end{tabular}

The number of patients with thoracic CT findings was 64; among those, $32.8 \%$ had main pulmonary artery involvement, $28.1 \%$ had segmental branch involvement, and $20.3 \%$ had terminal branch involvement.

The CT findings have been presented in Table 4.

Table 4. BT findings.

\begin{tabular}{lll}
\hline BT bulgusu & Var & Yok \\
\hline Main pulmonary artery involvement & $21(\% 32.8)$ & $43(\% 67.2)$ \\
Segmental branch involvement & $18(\% 28.1)$ & $46(\% 71.9)$ \\
Terminal branch involvement & $13(\% 20.3)$ & $51(\% 79.7)$ \\
\hline
\end{tabular}

Among the 165 patients included in the study, 60 had died in the hospital. Among these, 28 were female and 32 were male.

The relationship between mortality and low systolic blood pressure $(\mathrm{p}=0.003)$, low diastolic blood pressure $(\mathrm{p}<0.05)$ and tachycardia $(\mathrm{p}=0)$ was found to ne significantly different. The relation between mortality and high levels of urea $(p<0.05)$, creatinine $(p<0.05)$, d-dimer $(p<0.05)$, CK$\mathrm{MB}(\mathrm{p}<0.05)$, troponin $(\mathrm{p}<0.05)$ and lactate $(\mathrm{p}<0.05)$ was significant as well. The relationship between mortality and duration of intensive care unit stay $(\mathrm{p}<0.05)$, hospital stay $(\mathrm{p}<0.05)$ and duration of mechanical ventilation $(\mathrm{p}<0.05)$ was also significant.

A significant relation was determined between right bundle branch block in ECG and mortality $(p<0.05)$. The relationship between ECG findings with mortality has been presented in Table 5 .
Table 5. ECG findings related to mortality.

\begin{tabular}{llll}
\hline EKG finding & $\begin{array}{l}\text { Hastane içi } \\
\text { mortalite }(+)\end{array}$ & $\begin{array}{l}\text { Hastane içi } \\
\text { mortalite }(-)\end{array}$ & p \\
\hline Sinüs tachicardia & $14(\% 38.9)$ & $22(\% 61.1)$ & 0.82 \\
ST depretion & $4(\% 50)$ & $4(\% 50)$ & 0.47 \\
ST elevation & $0(\% 0)$ & $2(\% 100)$ & 0.52 \\
T dalga değişikliği & $3(\% 50)$ & $3(\% 50)$ & 0.67 \\
S1Q3T3 & $0(\% 0)$ & $1(\% 100)$ & 1 \\
Atrial Fibrilation & $21(\% 56.8)$ & $16(\% 43.2)$ & 0.005 \\
Sağ dal bloğu & $13(\% 68.4)$ & $6(\% 31.6)$ & $\mathrm{P}<0.05$ \\
\hline
\end{tabular}

The relationship of ECHO and CT findings with mortality was found to be insignificant.

A significant relationship was determined between the duration of mechanical ventilation and high pulse rate $(\mathrm{p}<0.05)$, low systolic blood pressure $(\mathrm{P}<0.05)$, low diastolic blood pressure $(p<0.05)$, high BUN level $(p<0.05)$, high lactate level $(\mathrm{p}<0.05)$ and high d-dimer level $(\mathrm{p}<0.05)$.

No significant relation was determined between the level of ionized calcium and mortality $(p=0.154)$. However, a significant relation was observed between a high ionized calcium level and duration of mechanical ventilation $(\mathrm{p}=0.019)$ (Table 6).

Tablo 6. Mechanical ventilator usage rates.

\begin{tabular}{llll}
\hline & MV using(+) & MV using(-) & P \\
\hline Age,median(IQR) & $73(17)$ & $68.50(21)$ & $\mathrm{P}<0.05$ \\
Cender n(\%) & & & \\
Female & $29(\% 30.9)$ & $65(\% 69.1)$ & 0.83 \\
Male & $23(\% 32.4)$ & $48(\% 67.6)$ & 0.83 \\
Tï 2 DM, n(\%) & $5(\% 26.3)$ & $14(\% 73.7)$ & 0.79 \\
CAD, n(\%) & $7(\% 41.2)$ & $10(\% 58.8)$ & 0.36 \\
\hline
\end{tabular}

No significant relation was observed between ECG, ECHO or CT findings and the rate of need for mechanical ventilation.

The correlation tests revealed a low correlation between the ionized calcium level and age, systolic blood pressure, saturation, $\mathrm{PO}_{2}$, lactate, troponin, d-dimer, urea, creatinine levels, and durations of mechanical ventilation, hospital stay and intensive care unit stay.

\section{Discussion}

It has been suggested that hypocalcemia leads to increased mortality rates among intensive care unit patients; however, despite the high incidence of hypocalcemia, no randomized controlled studies is yet present in the literature investigating the benefits and risks of calcium replacement in intensive care patients with hypocalcemia. However, medical treatment is recommended in patients with mild hypocalcemia who do not present with clinical findings [7].

Ionized calcium has been observed to decrease during abdominal aortic surgeries due to ischemia and hypovolemia [8].

Andreas Link et al. investigated the relation of the total calcium/ionized calcium rate with mortality in intensive care unit patients with citrate anticoagulation during renal replacement therapy, and observed a correlation between 28- 
day-mortality and hepatic and multi-organ dysfunction [9].

Fanster et al. detected high ionized calcium levels in intensive care unit patients with sepsis. These patients were serious clinical patients with hypotension and sepsis, and who required blood transfusion. Following blood transfusion, citrate was demonstrated to have a role in decreased ionized calcium. Hypercalcemia has been observed in vitamin D intoxication and immobilization. İonized calcium levels were found to be low in sepsis, shock, multiple transfusions and renal failure [10].

Carlstedt et al. demonstrated that high parathormone levels and hypocalcemia was correlated with the severity of the disease and poor prognosis in critically affected patients [11].

In a study conducted on 15409 intensive care unit patients, hypocalcemia was determined at a rate of $62 \%$, and that moderate hypercalcemia was shown to be correlated with low mortality, and yet again, a moderate hypocalcemia was correlated with an increased risk of death [12].

In a study conducted on dogs, low ionized calcium levels were observed to be correlated with delayed duration of intensive care and hospital stay [13].

Forsythe et al. evaluated the relationship between parenteral calcium replacement and mortality, multiple-organ failure and intensive care unit costs in critically affected intensive care unit patients. A significant, but not a high increase was observed in serum ionized calcium concentration following parenteral application of calcium. Clearly defined benefits of calcium replacement have been demonstrated in critically affected patients [14].

The study of Igbal et al. has retrospectively evaluated 153 patients in Saudi Arabia who have presented within one year, and revealed a negative correlation between hypocalcemia and the severity of the disease, whereas no effect of calcium in short or long term mortality [15].

In a study evaluating mortal myocardial depression and circulatory collapse, sedated rats were forced into circulatory collapse, and the mean arterial pressure, cardiac index, systemic vascular resistance and left ventricle contractility were measured. Delayed response to shock was observed in a group of rats, which was related to low ionized calcium level [16].

Steele et al. investigated the clinical effects of hypocalcemia in 1038 clinically affected patients, and the need for intensive care was demonstrated to be higher in severe hypocalcemic patients compared to mild hypocalcemic patients, and no difference was observed between the groups with regard to mortality. The survival rates were higher among the groups receiving calcium replacement [17].

In a study conducted on 337 children in the intensive care unit, no significant correlation was observed between 10-daymortality and low level of ionized calcium; however, a significant correlation was observed with the duration of intensive care unit stay. Low ionized calcium level was related to organ dysfunction [18].

Yamamoto et al. investigated the effect of ionized calcium concentration during cerebral hypothermia in patients with hypoxic ischemic encephalopathy, on the prognosis.

They demonstrated that intracellular inflow of calcium affected the neurological prognosis; however, hypothermia had led to recurrent neurological injury in a group of patients with high risk and low ionized calcium levels on admission [19].

Anastasopoulos et al. demonstrated that septic shock and fluctuations in plasma calcium concentrations were risk factors for development of polyneuropathy and myopathy in critically affected patients [20].

In a study investigating a group of patients with asthma, where the abnormalities in bivalent ion concentrations were recovered using IV magnesium, the calcium/magnesium ratio was observed to be increased in the study group compared to the placebo group [21].

A completely different relationship was determined between calcium and acid-base values in the arterial blood of patients with chronic obstructive pulmonary disease compared to patients with acid-base disorder only [22].

In a study investigating calcium, ionized calcium and magnesium levels during cardiovascular by-pass, the magnesium level was found to be significantly elevated at the beginning of perfusion in patients who had developed cardiac arrest during the surgery and been resuscitated, and returned to normal at the end of the operation. Since the ATP will be degraded and the level of ionized calcium will be reduced during cardiac arrest and hence the ischemia, the decrease in the magnesium level was related to the decrease in the calcium level. During cardiopulmonary by-pass, magnesium replacement was recommended; however, it was observed that calcium replacement was beneficial only after partial bypass and when the cardiac load had been completely gained back [23].

\section{Conclusion}

We could not find any study in the literature investigating the effects of ionized calcium on the prognosis and mortality in pulmonary embolism. In our study, the relationship between the ionized calcium level and mortality was not statistically significant; however, a significant correlation was observed between the increase in the ionized calcium level and the need for mechanical ventilation.

Although no clear relation between ionized calcium level and mortality was demonstrated, a significant correlation observed for the duration of mechanical ventilation suggests that ionized calcium can be used as a marker in the prognosis of patients with pulmonary embolism. However, further studies are needed on the subject.

\section{References}

[1] Konstantinides, S. Acute Pulmonary Embolism. N Engl J Med. 2008, 359, 2804.

[2] Akkoclu A. Destek tedavisi ve prognoz. Pulmoner Tromboemboli. Eskisehir: ASD Toraks Yayinlari 2001: 139-58. 
[3] Zaloga GP. Hypocalcemia in critically ill patients. Crit Care Med, 1992; 20: 251-262.

[4] Katrina A. Leone, Calcium, Magnesium, and Phosphorus Emergency Medicine, 166, 14051417.

[5] King R, Cooney RN. Hypocalcemia and hypercalcemia. In: Fink MP, Abraham E, Vincent JL, Kochanek PM (editors). Textbook of Critical Care, 5th Ed., Elsevier Saunders, 2005: 79-81.

[6] Desai TK, Carlson RW, Geheb MA. Prevalence and clinical implications of hypocalcemia in acutely ill patients in a medical intensive care setting. Am J Med 1988; 84: 209-314.

[7] Moritoki Egi, MD; Inbyung Kim, PhD; Alistair Nichol, PhD; Edward Stachowski, MD; Craig J. French, MB; Graeme K. Hart, MD; Colin Hegarty, BSc; Michael Bailey, PhD; Rinaldo Bellomo, MD, Ionized calcium concentration and outcome in critical illness, Crit Care Med 2011; 39:314-321.

[8] S. Jankowsky, J Knighton,R Dunnil and D. Dickson. Changes in iyonized calcium consentrations and asid base status during abdominal aortic vascular surgery. British journal of anaesthesia 1998;81,965,967.

[9] Andreas Link, Matthias Klingele, Timo Speer, Ranja Rbah, Janine Pöss, Anne Lerner-Gräber, Danilo Fliser and Michael Böhm, Total-to-ionized calcium ratio predicts mortality in continuous renal replacement therapy with citrate anticoagulation in critically ill patients. Link et al. Critical Care 2012, 16:R97.

[10] Jameson Forster, Luigi Querusio, Kenneth W. Burchard, Hypercalcemia in Critically Surgical Patients Eur J Clin. Invest. 1998 nov; 28(11):898-903.

[11] Carlstedt F, Lind L, Rastad J, Stjernström H, Wide L, Ljunghall S. Parathyroid hormone and ionized calcium levels are related to the severity of illness and survival in critically ill patients. Crit Care Med. 1990 Aug; 18(8):851-7.

[12] Zhang Z, Xu X, Ni H, Deng H. Predictive value of ionized calcium in critically ill patients: an analysis of a large clinical database MIMIC II. Published: April 15, 2014 DOI: 10.1371/ journal. pone. 0095204.

[13] Holowaychuk MK, Hansen BD, DeFrancesco TC, Marks SL. Ionized hypocalcemia in critically ill dogs. Journal of Veterinary Internal Medicine. Volume 23, Issue 3, May/June 2009, Pages 509-513.
[14] Forsythe RM, Wessel CB, Billiar TR, Angus DC, Rosengart MR Parenteral calcium for intensive care unit patients. Ann Thorac Med. 2008 Apr; 3(2):57-9. doi: 10.4103/18171737.39638 .

[15] Iqbal M, Rehmani R, Hijazi M, Abdulaziz A, Kashif S. Hypocalcemia in a Saudi intensive care unit. Ann Thorac Med. 2008 Apr-Jun; 3(2): 57-59.

[16] R. Busund, L. Balteskard, G. et al. Fatal myocardial depression and circulatory collapse associated with complement activation induced by plasma infusion in severe porcine sepsis Article first published online: 1 SEP 2011 DOI: 10.1111/j.1399-6576.1995.tb05600.

[17] Tom Steele, Ruwanthi Kolamunnage-Dona, Colin Downey, Cheng-Hock Toh, and Ingeborg Welters. Assessment and clinical course of hypocalcemia in critical illness. Crit Care. 2013; 17(3): R106.

[18] Ionized hypocalcemia is an early event and is associated with organ dysfunction in children admitted to the intensive care unit Pediatr Int. 2014 Oct 7. doi: 10.1111/ped.12438.

[19] Yamamoto Y, Ibara S, Tokuhisa T. et.al. Calcium concentration in hypoxic-ischemic encephalopathy during hypothermia. Pediatrics International, Volume 57, Issue 1, February 2015, Pages 64-67.

[20] Anastasopoulos D, Kefaliakos A, Michalopoulos A. Anastasopoulos et al. Is plasma calcium concentration implicated in the development of critical illness polyneuropathy and myopathy Critical Care 2011, 15:R247 http://ccforum.com/content/15/5/R247.

[21] Scand J. Clin Lab Invest. Ionized magnesium levels and the ratio of ionized calcium to magnesium in asthma patients before and after treatment with magnesium 2005;65(8):659-70.

[22] Vadstrup S, Wandrup J. Ionized calcium in blood: studies on patients with pulmonary disease.. J Intern Med. 1991 Sep; 230(3):239-43.

[23] Fuchs C, Brasche M, Spieckermann PG, Kirchhoff G, Regensburger D, Koncz J. Cardiovasc Surg (Torino). Divalent ions and myocardial function during cardiopulmonary by-pass (CPB). Changes of total calcium, ionizedcalcium, and magnesium in plasma. 1975 Sep-Oct; 16(5):476-83. 